\title{
The vertical dimension: A significant cue in the preschool child's concept of "bigger"
}

\author{
BARBARA W.S. POTEAT and ROBERT (' HULSEBUS,I \\ Furman Unitersity, Greenville, $S$. $C$.
}

The hypothesis tested is that 5- and 6-year-old preschool children when asked to choose between geometric solids will select as "bigger" thosc objects having greater verticulity. For each pair of solid three-dimensional objects in eight displays, the 5- and 6-year-olds $(N=25)$ indicated the "bigger" figure to be the solid having the greater vertical dimension $(p<.001)$. For all of the displays the choice patterns differed significantly from those of a control group) of 25 college freshmen. The r'sults suggest that the vertical dimension may be the salient mislcading perceptual cue in studies of conservation.

lnvestigations have suggested that for size judgments young children rely primarily on perceptual features of the stimuli. This is true particularly before the child has acquired the concept of conservation. Between the ages of four and seven, during what Piaget refers to as the stage of intuitive thought, the child focuses on a single aspect of a situation thereby relying on inappropriate cues in conservation studies (Berlyne, 1964; Flavell, 1963; Wallach, Wall, \& Anderson, 1967; Wohlwill, 1960, 1967). Work by Lumsden \& Poteat (1968) revealed the importance of the vertical dimension in judgments of comparative size made by pre-school children. In a situation in which children were asked to state which one of a pair of two-dimensional figures was "bigger," 5and 6-year olds judged the bigger figure to be that having the greater vertical dimension.

The present study continues the investigation of the disproportionate influence of the vertical dimension by introducing three-dimensional objects as test stimuli. The hypothesis tested is that 5- and 6-year olds, when presented with geometric solids, will select as "bigger" those objects having the greater verticality.

\section{SUBJECTS}

Kindergarten children $(\mathrm{N}=25)$ ranging in age from 5 years 6 months to 6 years 7 months served as experimental Ss. Control Ss were 25 male college freshman, 18 and 19 years old.

\section{STIMULI}

Four stimulus displays, each consisting of a pair of solid three-dimensional objects (cylinders. cones, and rectangles) were used. The necessary ambiguity was achieved by constructing the stimuli so that members of each pair had very similar volumes. Two displays were equal in volume and in the other two displays differences in volume favored the shorter object of each pair. Since Displays 1 and 3 weighted the choice of the shorter objects by $9 \%$ and $6 \%$ respectively, the shorter members should have been chosen as "bigger." In fact, this did not affect the experimental situation; although it could have been an artifact militating against the ambiguity of the choice for the control group. The lateral position of the items in each basic display was reversed to provide two sub-displays, designated $\mathrm{A}$ and $\mathrm{B}$. In all $\mathrm{A}$ displays the item with the greater vertical dimension appeared on the right, in $B$ displays on the left.

Displays 1A and 1B: two upright cardboard cylinders, painted green ( 3 in. $\times 9.12$ in. and 4 in. $x 5.62$ in.). The shorter of these was $9 \%$ larger by volume.

Displays $2 \mathrm{~A}$ and $2 \mathrm{~B}$ : two wooden rectangular solids ( 3 in. $x 3$ in. $x$ 9 in. and 4.06 in. $x 4$ in. $x 5$ in.), painted gray.

Displays $3 \mathrm{~A}$ and $3 \mathrm{~B}$ : two upright cardboard cones $(5.75$ in. $x$ 18.25 in. and 8.48 in. $x 8.87$ in.), painted blue. The shorter of these was $6 \%$ larger by volume.

Displays 4A and 4B: the same gray wooden blocks as in Display 2 above. with the 3 in. $\times 3$ in. $\times 9$ in. block being presented horizontally so that its dimensions were now 3 in. $x 9$ in. $x 3$ in. This. in effect, gave the 4 in. $x 4$ in. $x 5$ in. block the greater vertical dimension within this display.

\section{PROCHDURE}

Relatively quiet rooms, free from distraction, were chosen for testing both the experimental and the control group. To restrict comparisons to the stimulus items themselves, the rooms chosen had plain walls painted in a solid color. Stimuli were displayed on large horizontal surfaces, unmarked and free of other objects. Ss were tested individually and were seated across the display area from $E$. A distance of approximately $3 \mathrm{ft}$ was maintained between the $S$ and the stimulus display. No restriction was placed on the lateral movement of the $S$. For each presentation the stimulus items themselves were kept 5 in. apart.

As each display was presented $\mathbf{E}$ asked the question, "Which is bigger?" Two Ss in the control group $(\mathrm{N}=25)$ asked whether the comparison might be an ambiguous one and requested clarification of the question. The question was repeated and the Ss proceeded to make a choice without further query. None of the children in the experimental group asked questions.

To prevent comparison during the alternation of displays, the objects not on display were hidden from the Ss by a screen. Possibly biasing effects of the order of presentation were counterbalanced by using 10 random sequences and their reverse. RESULTS

The responses of both the kindergarten group and the college freshmen were consistent across the pairs of laterally reversed displays. This allowed pooling of the data for each pair within each group. The number of Ss choosing the object having the greater vertical dimension as the bigger one within each display is shown in Table 1.

The primary hypothesis was that the kindergarten children would choose as "bigger," significantly more than $50 \%$ of the time, the figure having the greater vertical dimension. The second hypothesis was that the control group's choices would not differ significantly from a 50:50 split assuming that the choice across pairs equated for volume would be an ambiguous one. The chi-square analysis of the choices between the two objects in each set of displays for both groups is shown in Table 2.

The kindergarten group's choices were significantly different from a chance 50:50 split beyond the .01 level and, as can be seen in Table 1, they chose as bigger the figure having greater verticality. The ambiguity of the selection for the control group was confirmed by the insignificant deviation of the control group choices from a 50:50 split at the .01 level.

A chi-square analysis was conducted on the particular choice patterns of the control and experimental groups for each set of displays, as a test of independence of the age of the Ss and the influence of the vertical dimension on their judgments of "bigger." Applying the hypothesis to this test, it was predicted that the choice patterns would not be independent of the age of the Ss. In addition Fisher's Exact Test of Significance for a 2 by 2 table was used testing the null hypothesis that chance accounted for any existing association (Hays, 1963). The chi-square values and the exact probabilities are shown in Table 3. These support the hypothesis that choices were not independent of the age of the Ss and, in the case of the Fisher Exact Test, allow us to reject the null hypothesis.

Table 1

Number and Percentage of Ss Selecting as "Bigger" the Object Having the Greater Vertical Dimension

\begin{tabular}{lcc}
\hline Stimulus Display & Kindergarten $(\mathrm{N}=25)$ & College $(\mathrm{N}=25)$ \\
\hline IA \& 1B (cylinders) & $50(100 \%)$ & $15(30 \%)$ \\
2A \& 2B (rectangles) & $50(100 \%)$ & $18(36 \%)$ \\
3A \& 3B (cones) & $50(100 \%)$ & $25(50 \%)$ \\
4A \& 4B (rectangles) & $45(90 \%)$ & $17(34 \%)$ \\
\hline
\end{tabular}


Table 2

Chi-Square Analyses of Choice Patterns of Kindergarten $(N=25)$ and Control Group $(\mathbf{N}=\mathbf{2 5})$

\begin{tabular}{lcc}
\hline Stimulus Display & $\begin{array}{c}(\mathrm{df}=1) \\
\text { Kindergarten } \\
\text { Chi-Square Value }\end{array}$ & $\begin{array}{c}\text { College } \\
\text { Chi-Square Value }\end{array}$ \\
\hline 1A \& 1B & $* * 16.666$ & 2.083 \\
2A \& 2B & $* * 16.666$ & .999 \\
3A \& 3B & $* * 16.666$ & .000 \\
4A \& 4B & $* * 9.523$ & 1.313 \\
\hline
\end{tabular}

**Significant at .01 level.

\section{DISCUSSION}

The results supported the hypothesis that the vertical dimension significantly influences the preschool child's size judgments of ambiguous three-dimensional objects, with those objects having the greater vertical dimension being chosen as "bigger." The control group's results supported the assumption that their choice patterns would reflect the ambiguity of the stimuli. As Lumsden \& Poteat (1968) have suggested, this disproportionate relevance of the vertical dimension could be a confounding factor in some of the studies of size conservation when preschool children are the Ss.

More constructively these results may clarify the dominance of perceptual processes over conceptual processes in the young child (Berlyne, 1964; Wohlwill, 1967). Wallach, Wall, \& Anderson (1967) call attention to the importance of misleading perceptual cues in conservation studies. The results here reported emphasize the role of the vertical dimension as such a potentially misleading perceptual cue. A partial explanation of this may be sought in the work of Piaget (1963), Piaget, Matalon, Vinh-Bang, \& Morf et al (1961) studying perceptual illusions. Finding consistent overestimation of the vertical in the horizontal-vertical illusion as well as in the "figure en equerre," Piaget and his co-workers have developed techniques to study "centrations" through a comparison of eye movements and fixations of Ss making perceptual comparisons. They find that these distributions account for the overestimation of the vertical and some of the changes in these illusions as a function of age.

The question of response availability has been raised by Griffiths, Shantz, \& Sigel (1967) studying methodological

Table 3

Analyses of the Choice Patterns of Kindergarten Group and College Freshmen Group Using Chi-Square and the Fisher Exact Probability Test

\begin{tabular}{lll}
\hline Stimulus Display & $\begin{array}{c}\text { Chi-Square } \\
(\mathrm{df}=1)\end{array}$ & Probability*** \\
\hline IA \& 1B & $* * 26.92$ & $1.85 \times 10^{-7}$ \\
2A \& 2B & $* * 23.53$ & $2.41 \times 10^{-6}$ \\
3A \& 3B & $* * 16.71$ & $3.99 \times 10^{-4}$ \\
4A \& 4B & $* * 16.64$ & $4.21 \times 10^{-4}$ \\
\hline
\end{tabular}

*"Significant at the 01 level.

**The confidence level for rejecting the null hypothesis being .01 , any probability below $1.0 \times 10^{-2}$ indicated significance. problems in conservation. Although the word "bigger" is a relational term, and may imply "more," within the context of this experimental situation-the question of response availability does not arise. It should be noted that the kindergarten group made no attempt to use the word "same" but, as mentioned earlier, only two of the 25 college students asked if they could use judgments of "same."

In studies of discrimination of line Rudel \& Teuber (1963) briefly speculated on the biologic utility of visual dependence on vertically oriented contours "reflecting their importance for the maintenance of upright posture [p. 897]." Sekuler \& Rosenblith (1964) suggested a different interpretation of Rudel and Teuber's results based on the relation of standard and comparison stimuli in such discrimination studies. However, our present study verifies the dependence of young children on the vertical dimension in at least certain choice situations.

Explanations of this phenomenon lead to interesting speculation, but we would suggest that there is practical importance in a further investigation attempting to discover at what age the vertical dimension no longer exerts a significant influence in choice situations of the sort reported here. REFERENCES

BERLYNE, D. E. Recent developments in Piaget's work. In Harper, Anderson, Christensen, and Hunka (Eds.), The cognitive processes: Readings. Englewood Cliffs, N.J.: Prentice-Hall, 1964. Pp. 311-324.

FLAVELL, J. H. The developmental psychology of Jean Piaget. Princeton, N.J.: van Nostrand, 1963.

GRIFFITHS, J. A., SHANTZ, C. A., \& SIGEL, I. E. A methodological problem in conservation studies: the use of relational terms. Child Development, 1967, 38, 841-848.

HAYS, W. L. Statistics for psychologists. New York: Holt, Rinehart, \& Winston, 1963.

LUMSDEN, E. A., \& POTEAT, B. W.S. The salience of the vertical dimension in the concept of "bigger" in five- and six-year olds. Journal of Verbal Learning \& Verbal Behavior, 1968, in press.

PIAGET, J. Le developpement des perceptions en fonction de l'age. In J. Piaget, P. Fraisse, E. Vurpillot, and R. Frances (Eds.), Traite de psychologie experimentale: VI, La Perception. Paris: Presses Universitaires de France, 1963.

PIAGET, J., MATALON, B., VINH-BANG, MORF, A., et RUTSCHMANN, J. Recherches sur le developpement des perceptions. No. XLII-XLV, Archives de psychologie, 1961, 38, 23-200.

RUDEL, R. G., \& TEUBER, H. Discrimination of direction of line in children. Journal of Comparative \& Physiological Psychology, 1963, 56, 892-898.

SEKULER, R. W., \& ROSENBLITH, J. F. Discrimination of the direction of line and the effect of stimulus alignment. Psychonomic Science, 1964, 1, 143-144.

WALLACH, L., WALL, J. A., \& ANDERSON, L. Number conservation: the roles of reversibility, addition-subtraction, and misleading perceptual cues. Child Development, 1967, 38, 425-442.

WOHLWILL, J. F. Developmental studies of perception. Psychological Bulletin, 1960, 57, 249-288.

WOHLWILL, J. F. The mystery of the pre-logical child. Psychology Today, $1967,1,25-34$.

\section{NOTES}

1. Mrs. Poteat is now at the University of South Carolina.

2. The authors sincerely appreciate the assistance of C. Russell Clifton, $\mathrm{J}_{\mathbf{r}}$, in the initial preparation and collection of data for this study. 